\title{
SUSTENTABILIDADE DA HABITAÇÃO DE INTERESSE SOCIAL: O CASO DO CONJUNTO HABITACIONAL CÉSAR SANTANA FILHO EM VIÇOSA-MG
}

\author{
Aline Werneck Barbosa de Carvalho ${ }^{1}$
}

\author{
Italo Stephan ${ }^{2}$
}

\section{Marina Galatro Mendes Guedes ${ }^{3}$}

\begin{abstract}
RESUMO
A sustentabilidade de um projeto de habitação de interesse social deve ser pensada de maneira ampla, abrangendo a dimensão social como forma de prover o direito à moradia digna, garantindo padrão mínimo de habitabilidade, infraestrutura, mobilidade e equipamentos urbanos e sociais. Neste artigo procura-se refletir sobre a sustentabilidade social do Programa Minha Casa, Minha Vida, a partir do estudo de caso do conjunto habitacional César Santana Filho, construído na cidade de Viçosa-MG. A metodologia adotada abrangeu pesquisa documental e de campo, abrangendo o levantamento de dados documentais na Secretaria Municipal de Políticas Sociais e no Instituto de Planejamento Municipal de Viçosa, o levantamento fotográfico do conjunto habitacional seguido de observação direta dos aspectos físico-territoriais do empreendimento e a aplicação de questionários a uma amostra de 40 moradores, com a finalidade de identificar sua percepção quanto à qualidade do conjunto. A sustentabilidade social do Programa foi analisada a partir da caracterização do empreendimento e do público alvo, complementada pela percepção dos beneficiários acerca da adequação do novo conjunto habitacional comparativamente às condições de moradia anterior. Os resultados indicaram que praticamente todas as condições de infraestrutura urbana e de acesso ao trabalho e aos equipamentos de saúde, educação, comércio e lazer foram consideradas piores do que aquelas vivenciadas pelos entrevistados nos seus bairros de origem, exceto no caso da unidade habitacional propriamente dita. Estes resultados apontam problemas de acessibilidade e mobilidade urbana, que isolam os moradores do restante da cidade e reforçam a segregação socioespacial, comprometendo a sustentabilidade social do empreendimento.
\end{abstract}

\footnotetext{
${ }^{1}$ Arquiteta e urbanista / UFMG, Doutora em Arquitetura e Urbanismo / FAUUSP, Professora do Departamento de Arquitetura e Urbanismo / UFV. E-mail: alinewbc@gmail.com

${ }^{2}$ Arquiteto e urbanista / UFRJ, Doutor em Arquitetura e Urbanismo / FAUUSP, Professor do Departamento de Arquitetura e Urbanismo / UFV. E-mail: stephan@ufv.br

${ }^{3}$ Estudante do curso de Arquitetura e Urbanismo / UFV. Bolsista FAPEMIG. E-mail: marina.galatro@gmail.com
} 


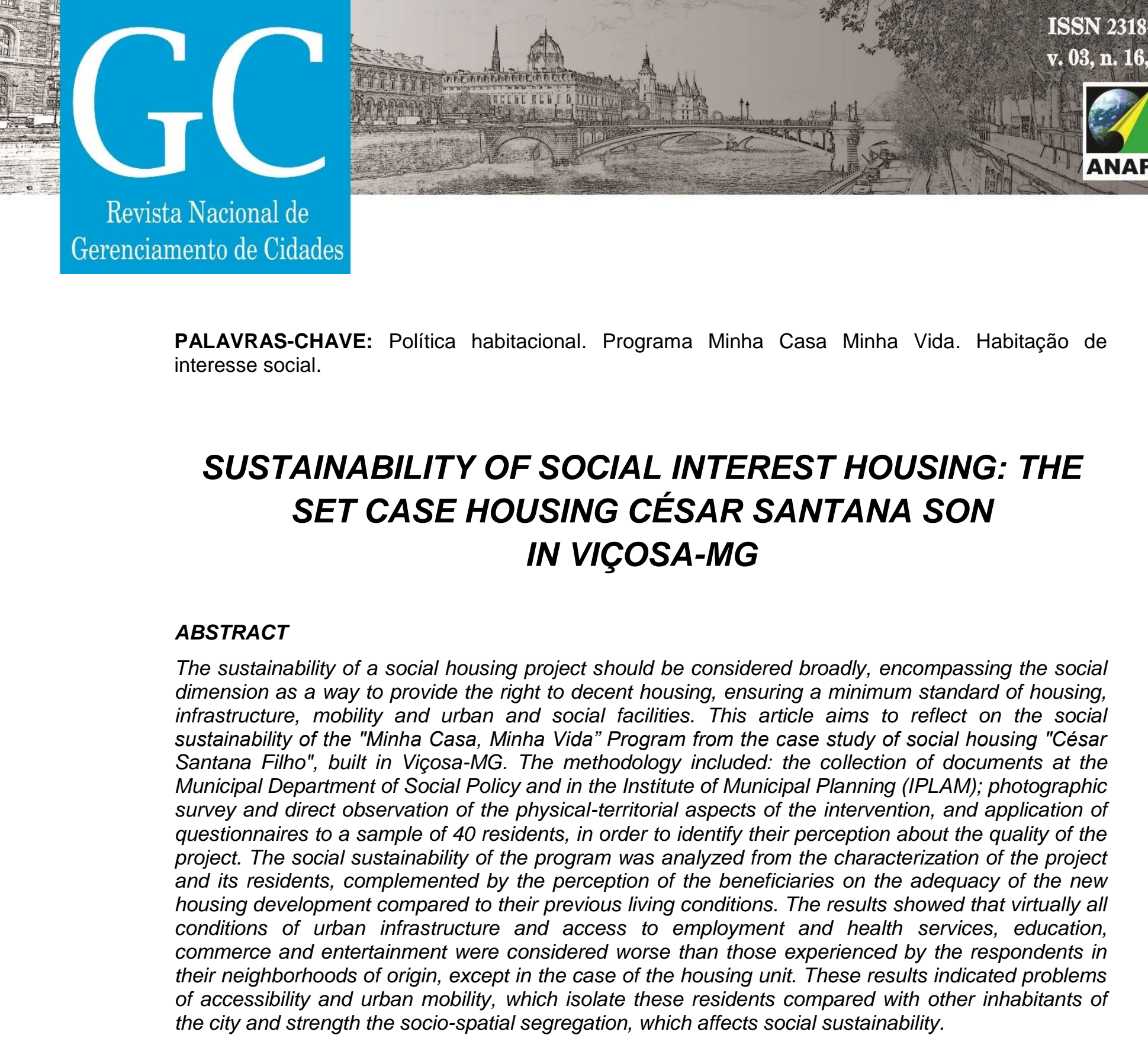

PALAVRAS-CHAVE: Política habitacional. Programa Minha Casa Minha Vida. Habitação de interesse social.

\begin{abstract}
The sustainability of a social housing project should be considered broadly, encompassing the social dimension as a way to provide the right to decent housing, ensuring a minimum standard of housing, infrastructure, mobility and urban and social facilities. This article aims to reflect on the social sustainability of the "Minha Casa, Minha Vida" Program from the case study of social housing "César Santana Filho", built in Viçosa-MG. The methodology included: the collection of documents at the and its residents, complemented by the perception of the beneficiaries on the adequacy of the new housing development compared to their previous living conditions. The results showed that virtually all conditions of urban infrastructure and access to employment and health services, education, dhe respondents in of accessibility and urban mobility, which isolate these residents compared with other inhabitants of
\end{abstract}

KEYWORDS: Housing policy, "Minha Casa Minha Vida” Program, Low income housing.

\title{
SOSTENIBILIDAD DE VIVIENDA DE INTERÉS SOCIAL: EL VIVIENDA SET CASO CÉSAR SANTANA HIJO EN VIÇOSA-MG
}

\begin{abstract}
RESUMEN
La sostenibilidad de un proyecto de vivienda social debe abarcar la dimensión social como una forma de ofrecer el derecho a una vivienda digna, garantizar un nivel mínimo de la vivienda, infraestructuras, movilidad y servicios urbanos y sociales. En este artículo se pretende reflexionar sobre la sostenibilidad social del "Programa Minha Casa, Minha Vida", desde el estudio de caso de vivienda social "César Santana Filho", construido en Viçosa-MG. La metodología incluyó la recolección de documentos en la Secretaría Municipal de Política Social y el Instituto de Planificación Municipal de Viçosa (IPLAM); levantamiento fotográfico y observación directa de los aspectos físico-territoriales de la intervención, y aplicación de cuestionarios a una muestra de 40 residentes, con el fin de identificar
\end{abstract}




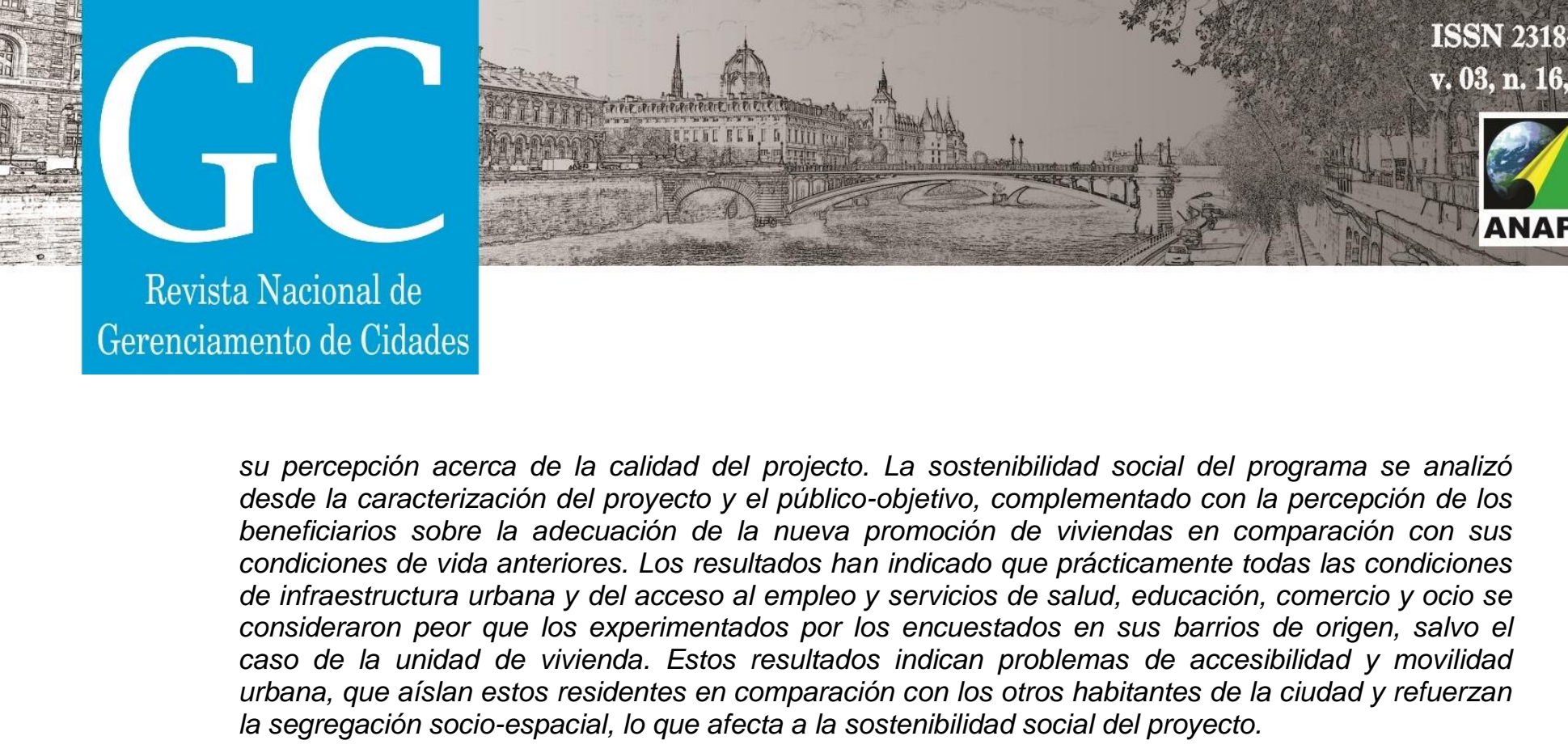

su percepción acerca de la calidad del projecto. La sostenibilidad social del programa se analizó desde la caracterización del proyecto y el público-objetivo, complementado con la percepción de los beneficiarios sobre la adecuación de la nueva promoción de viviendas en comparación con sus condiciones de vida anteriores. Los resultados han indicado que prácticamente todas las condiciones

PALABRAS-CLAVE: Política de Vivienda. Programa "Minha Casa,Minha Vida". Vivienda Social.

\section{INTRODUÇÃO}

A sustentabilidade da habitação de interesse social deve ser pensada de maneira ampla, abrangendo não só o aspecto ambiental, mas também sua dimensão social como forma de prover o direito à moradia digna, por meio da garantia de um padrão mínimo de habitabilidade, infraestrutura, mobilidade e equipamentos urbanos e sociais.

Esta preocupação estende-se aos conjuntos habitacionais produzidos pelo Programa Minha Casa, Minha Vida (PMCMV), que é o mais importante programa habitacional brasileiro desde a atuação do BNH - Banco Nacional de Habitação (1964 -1986), sobretudo pela amplitude espacial e quantitativa das suas ações. Porém, a literatura tem apontado severas críticas relativas à qualidade da produção habitacional, principalmente nas grandes cidades, pela sua desarticulação com a política urbana, cujo resultado tem sido a localização de empreendimentos nas periferias das cidades, em áreas carentes de infraestrutura urbana e de equipamentos sociais e comunitários. (MARICATO, 2011; ROLNIK; KLINK, 2011; PENALVA; DUARTE, 2010; HIRATA, 2011).

Neste artigo procura-se refletir sobre a sustentabilidade social de um conjunto habitacional do PMCMV construído em Viçosa, pequena cidade localizada em Minas Gerais. Inicialmente, apresenta-se uma breve discussão do conceito de sustentabilidade. Em seguida, apresenta-se a análise do objeto empírico a partir da percepção dos beneficiários acerca da adequação do novo conjunto habitacional comparativamente às suas condições de moradia anterior. 


\section{Revista Nacional de}

\section{OBJETIVO}

Tem-se como objetivo refletir sobre a sustentabilidade social do Programa Minha Casa, Minha Vida a partir do estudo de caso do conjunto habitacional César Santana Filho construído na cidade de Viçosa-MG.

\section{METODOLOGIA}

Os resultados desse artigo são decorrentes da pesquisa de iniciação científica denominada Avaliação da Eficácia Social do Programa Minha Casa, Minha Vida em Viçosa-MG, financiada pela Fundação de Amparo à Pesquisa do Estado de Minas Gerais / FAPEMIG. A pesquisa foi realizada nos três conjuntos habitacionais construídos em Viçosa, com a finalidade de descrever as características dos empreendimentos e estabelecer relações entre suas características físicas e a satisfação dos moradores, comparativamente à sua condição anterior de moradia.

Neste artigo, destacamos apenas o caso do Conjunto Habitacional César Santana Filho. A metodologia de pesquisa compreendeu a coleta de dados primários e secundários. Os dados primários foram obtidos por meio do levantamento das fichas de cadastramento dos beneficiários arquivadas no Departamento de Habitação da Secretaria Municipal de Políticas Sociais, da aplicação de questionários aos moradores, e da observação direta do comportamento dos moradores nos conjuntos habitacionais estudados, registrados por meio de levantamento fotográfico e anotações de campo.

A partir das fichas de cadastramento dos beneficiários foi realizado o levantamento das características socioeconômicas das famílias residentes no conjunto residencial. Foram preenchidas tabelas utilizando-se o programa computacional Excel-versão 2007, contendo as seguintes informações: sexo do beneficiário, endereço anterior, estado civil, escolaridade, profissão, local de 
Revista Nacional de

Gerenciamento de Cidades

trabalho, número de filhos, número de pessoas que irão morar na casa, pessoas com necessidades especiais, usuário de cadeira de rodas, condições de moradia da família, faixa etária do chefe da família, renda familiar, tempo de moradia da família no município, e se recebe algum benefício do governo.

A aplicação dos questionários e a observação direta ocorreram nos meses de junho a dezembro de 2014. Para a elaboração do questionário foram definidos três constructos: a) caracterização do respondente e condições de habitação antes de mudar para o novo conjunto habitacional; b) percepção do morador quanto às condições de acesso e infraestrutura; c) percepção do morador quanto à moradia. Foram aplicados 40 questionários, correspondendo a 7,8\% de erro amostral e $95 \%$ de nível de confiança.

A observação direta e o levantamento fotográfico do conjunto foram feitos concomitantemente à visita destinada à aplicação dos questionários. O acesso dos pesquisadores foi facilitado pela atuação de dois moradores que haviam participado da Associação de Moradores. Durante a observação direta foram feitas anotações no diário de campo, constituindo dados importantes para a pesquisa.

Foram coletados dados secundários provenientes de documentos disponibilizados publicamente por órgãos governamentais e de pesquisa, como o Ministério das Cidades, IBGE e Prefeitura Municipal de Viçosa. A coleta destes dados compreendeu o levantamento do projeto arquitetônico do empreendimento no Instituto de Planejamento Municipal - IPLAM e consulta a relatórios e outros documentos da Secretaria Municipal de Políticas Sociais.

Os dados obtidos foram organizados sob a forma de quadros, tabelas, imagens, plantas baixas e mapas. Os questionários foram tabulados e analisados a partir da Estatística Descritiva, indicando-se a percepção dos moradores quanto às condições do empreendimento face às condições de moradia anterior. 


\section{Revista Nacional de}

\section{RESULTADOS}

\subsection{O conceito de sustentabilidade e a sustentabilidade social da habitação de interesse social}

O conceito de sustentabilidade é abrangente e ultrapassa a dimensão ambiental. Seu caráter interdisciplinar é utilizado em distintas abordagens, muitas vezes em conjunto com o termo desenvolvimento.

Sachs (1993), um dos pioneiros na discussão do conceito de desenvolvimento sustentável, destaca que a sustentabilidade somente é inteiramente definida quando compreende cinco dimensões: ecológica, econômica, espacial, cultural e social. A dimensão ecológica ou ambiental da sustentabilidade é a mais conhecida e talvez a mais abrangente do tema, associando-se ao conceito de desenvolvimento sustentável, à priorização do desempenho dos espaços com base na economia de recursos naturais e à Bioclimatologia ${ }^{4}$. Para este autor, a sustentabilidade ecológica consiste na "utilização dos recursos naturais, quando possível, renováveis, com maior eficiência; redução da utilização de combustíveis fósseis; redução do número de resíduos e poluição - promovendo a autolimitação do consumo; intensificação nas pesquisas para obtenção de meios mais eficientes e menos poluentes para o desenvolvimento do espaço urbano, rural e industrial, e desenvolvimento de normas adequadas para proteção ambiental com elementos de apoio econômicos legais e administrativos necessários para seu cumprimento". A sustentabilidade econômica consiste no "gerenciamento mais eficiente dos recursos e maiores investimentos tanto nos setores públicos como nos privados, além de procurar maior eficiência econômica em termos macrossociais e não apenas através do critério macroeconômico do empresário". A sustentabilidade espacial caracterizase por uma "configuração urbano-rural mais equilibrada entre os assentamentos urbanos e atividades econômicas; redução da concentração excessiva nas metrópoles; exploração racional das florestas e da agricultura através de técnicas

\footnotetext{
${ }^{4}$ A Bioclimatologia considera as condições climáticas, utilizando os recursos disponíveis na natureza.
} 
Revista Nacional de

Gerenciamento de Cidades

modernas e regenerativas; exploração da industrialização descentralizada; criação de uma rede de reservas naturais e da biosfera para proteção da biodiversidade". A sustentabilidade cultural consiste na "manutenção das raízes em todos os processos de modernização, agricultura, indústria; preservando as características naturais e da biosfera". Por fim, a sustentabilidade social consiste na "criação de um processo de desenvolvimento sustentável com melhor distribuição de renda e redução das diferenças sociais", em busca de uma maior equidade social (SACHS, 1993, p.13), isto é, com menor segregação social e espacial.

A dimensão social da sustentabilidade é também destacada por Mülfarth (2003), relacionada à forma de promover a busca pela igualdade social e valorização dos aspectos culturais.

Um projeto de habitação de interesse social que incorpore a noção de sustentabilidade deve ser pensado de maneira ampla, de modo a não excluir nenhuma das dimensões apontadas por Sachs (1993). Além dos aspectos construtivos e ambientais, diretamente relacionados com a qualidade do projeto arquitetônico, e dos aspectos econômicos relativos à relação custo-benefício da implantação do empreendimento, a política habitacional deve considerar as dimensões cultural, espacial e social da sustentabilidade, que decorrem da sua capacidade de promover a igualdade social, provendo aos beneficiários o direito à moradia digna como vetor de inclusão social, mediante a garantia de um padrão mínimo de habitabilidade, infraestrutura, saneamento ambiental, mobilidade, transporte coletivo, equipamentos e serviços urbanos e sociais.

No entanto, a implantação da habitação de interesse social sem a devida preocupação com o meio é uma tendência no cenário das cidades brasileiras, cujo resultado é a exclusão da camada de baixa renda dos locais privilegiados na cidade, devido ao interesse privado. Torna-se cada vez mais comum a construção de conjuntos habitacionais afastados desses locais e, em muitos casos, distantes de equipamentos e serviços coletivos e de uso social, comprometendo a sustentabilidade social desses empreendimentos. 


\section{Revista Nacional de}

\subsection{O Programa Minha Casa, Minha Vida em Viçosa e o Conjunto Habitacional César Santana Filho}

O município de Viçosa localiza-se na Zona da Mata de Minas Gerais. Possui população estimada em 72.000 habitantes, dos quais aproximadamente 93\% residem na área urbana (IBGE, 2010). Desde a década de 1970, a cidade tem passado por um processo de rápida urbanização, motivado principalmente pela expansão das atividades da Universidade Federal de Viçosa. Esta instituição foi criada em 1926, como Escola Superior de Agricultura e Veterinária e, até o final da década de 60, pouco influenciou no crescimento da cidade. Entretanto, com sua federalização, em 1969, a Universidade recebeu aporte financeiro substancial para sua expansão física, para a criação de novos cursos de graduação e pós-graduação e para o aumento do seu quadro de pessoal. Além da contratação de funcionários e professores, essa expansão atraiu um contingente populacional dos municípios vizinhos, bem como das áreas rurais, além do aumento da população estudantil, gerando uma grande demanda por habitação, infraestrutura e serviços na cidade. A partir do final da última década, com a implantação do Plano de Reestruturação e Expansão das Universidades Federais (REUNI), a cidade vem passando por novo processo de expansão urbana, motivado pela ampliação do número de vagas e pela criação de novos cursos na UFV e em outras universidades particulares instaladas na cidade.

Embora o município disponha de Plano Diretor e de leis urbanísticas de controle do uso e ocupação do solo, a falta de atuação mais decisiva do poder público municipal sobre o mercado imobiliário tem resultado num padrão de ocupação que concentra a população mais abastada nas áreas centrais e nos bairros servidos por infraestrutura, enquanto os bairros destinados à população de menor renda crescem em direção às encostas, ocupando áreas de relevo muito acidentado, ou em direção às porções mais distantes da mancha urbana. 

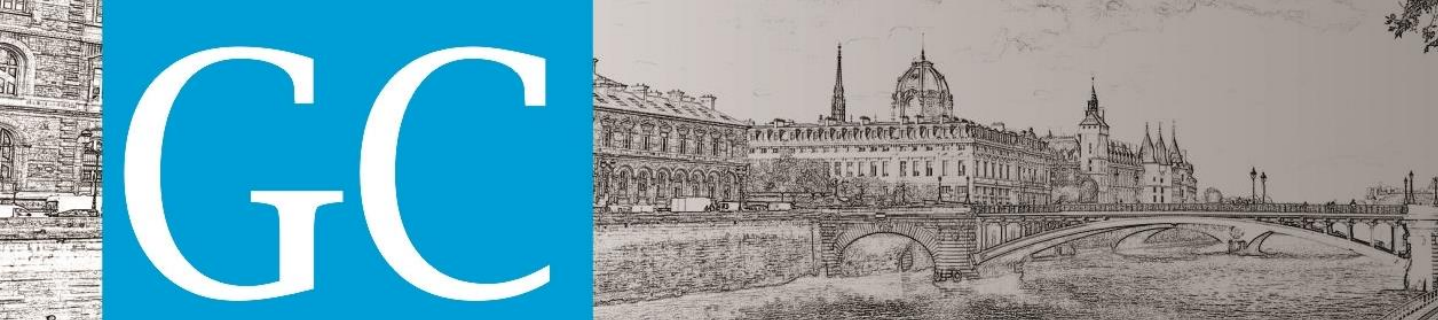

Revista Nacional de

Gerenciamento de Cidades

Nos anos de 2011 e 2012 foram implantados três empreendimentos do PMCMV na área urbana do município: conjuntos Benjamim José Cardoso (Coelha), César Santana Filho e Floresta. O conjunto César Santana Filho, mais conhecido como Sol Nascente, foi o terceiro empreendimento do PMCMV construído na cidade. Está localizado na Estrada dos Araújos, no Bairro São Francisco de Assis, distante cerca de 500m da entrada do conjunto Benjamin José Cardoso. (Figura 1).

Figura 1: Localização do Conjunto Habitacional César Santana Filho (Sol Nascente). Viçosa, MG
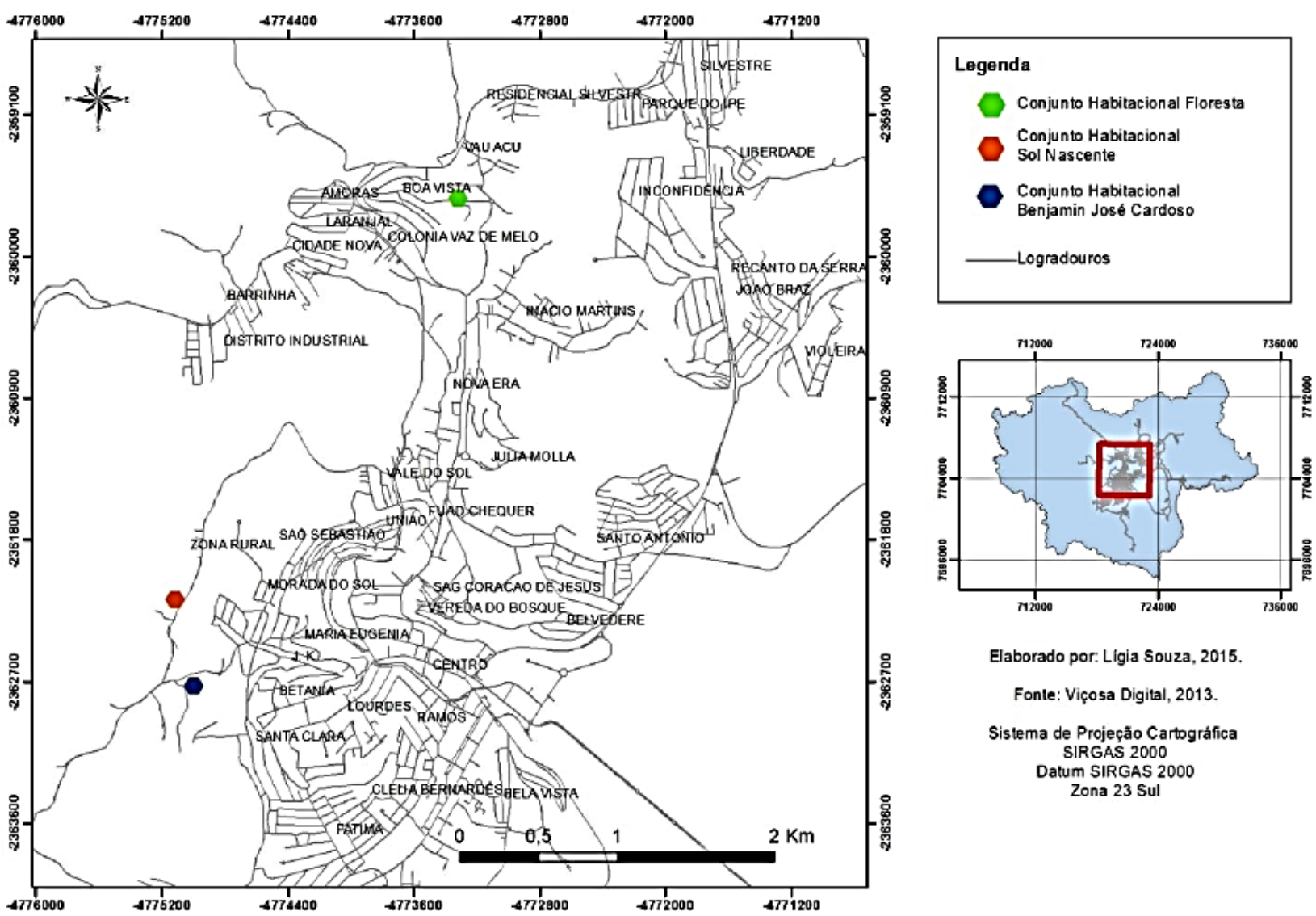

Elaborado por: Ligia Souza, 2015.

Fonte: Viçosa Digital, 2013.

Sistema de Projeção Cartográfica

Datum SIRGAS 2000

Zona 23 Sul

Fonte: Arquivo dos pesquisadores. Elaborado com o software ArcGIS 10.1.

O acesso feito pelo lado do conjunto Benjamin José Cardoso é mais próximo ao Centro da cidade, distando dele cerca de $2 \mathrm{~km}$, mas as condições de 


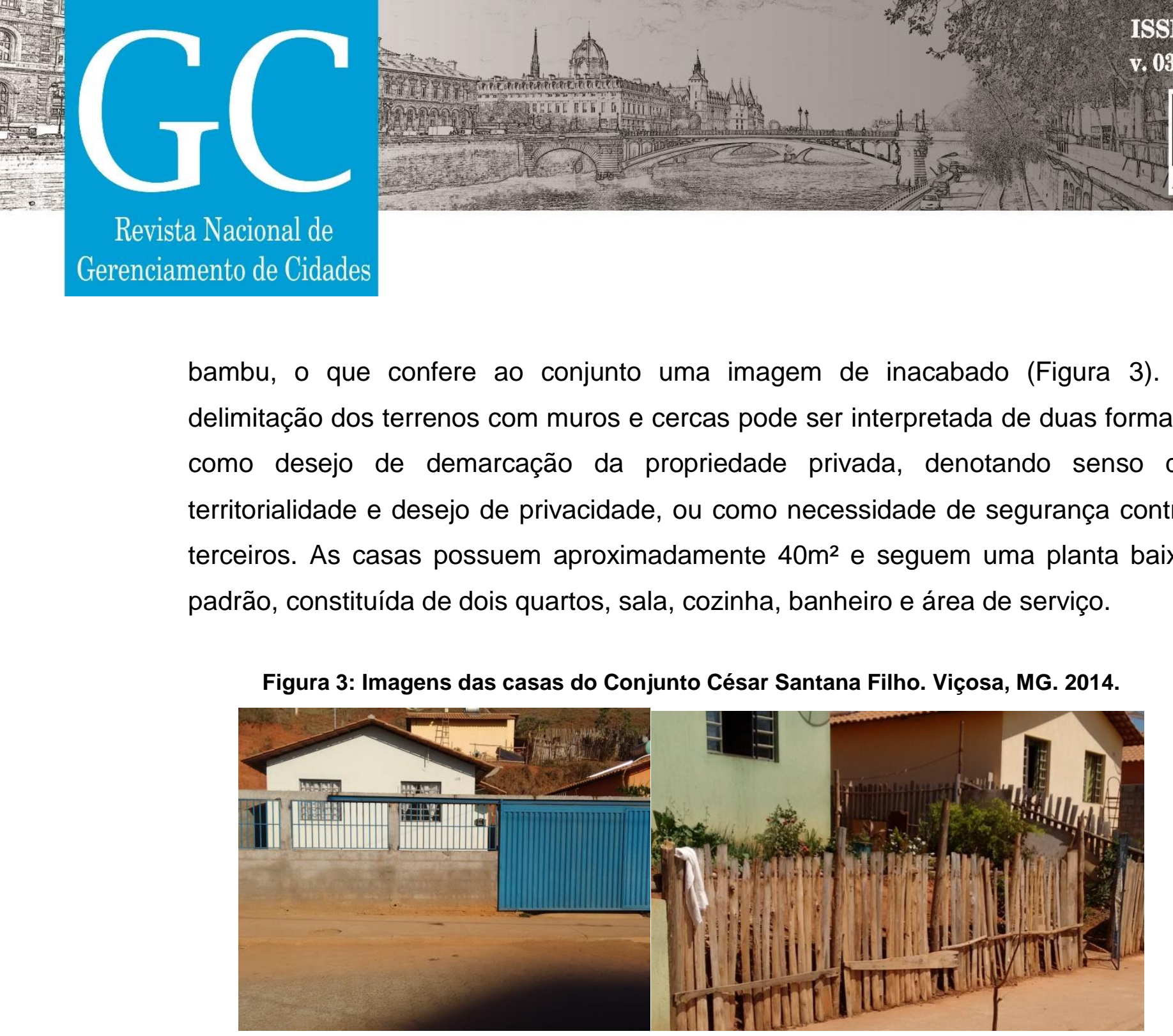

bambu, o que confere ao conjunto uma imagem de inacabado (Figura 3). A delimitação dos terrenos com muros e cercas pode ser interpretada de duas formas: territorialidade e desejo de privacidade, ou como necessidade de segurança contra terceiros. As casas possuem aproximadamente $40 \mathrm{~m}^{2}$ e seguem uma planta baixa padrão, constituída de dois quartos, sala, cozinha, banheiro e área de serviço.

Figura 3: Imagens das casas do Conjunto César Santana Filho. Viçosa, MG. 2014.

Fonte: Arquivo dos pesquisadores.

No interior do conjunto, o calçamento das vias é feito em blocos de concreto sextavado e encontra-se em boas condições. O empreendimento conta com rede de água, esgoto, energia elétrica domiciliar e pública, drenagem pluvial, coleta de lixo e, ainda precário, sistema de entrega dos Correios. Entretanto, o sinal telefônico para celulares é de baixa qualidade e não há telefonia fixa.

O posto de saúde mais próximo está localizado no Bairro Santa Clara, mas o acesso é difícil por causa das más condições de calçamento da via e do relevo. Além disso, o posto está subdimensionado para atender à demanda extra constituída pela população dos conjuntos habitacionais Benjamin José Cardoso e César Santana Filho. Nas imediações do conjunto não há escolas, creches, nem estabelecimentos comerciais, exceto um bar, que vende produtos de primeira necessidade, porém com preços mais altos do que os praticados pelos 


\section{Revista Nacional de}

Gerenciamento de Cidades

supermercados localizados no centro da cidade. Os principais estabelecimentos comerciais e equipamentos institucionais estão distantes cerca de $2 \mathrm{~km}$ do empreendimento.

Os moradores não contam com espaço para a realização de encontros ou reuniões; para as crianças há um parquinho localizado em uma área reservada para uso institucional, porém, encontra-se em péssimas condições de conservação. O terreno, por ser uma área inundável, foi reservado como "area non aedificandi" e tornou-se um local perigoso para o uso das crianças, seja pela falta de infraestrutura adequada (caminhos pavimentados para acesso aos brinquedos, iluminação, etc.), seja porque o terreno é utilizado como pasto para cavalos e como ponto de tráfico de drogas.

Quanto ao perfil dos beneficiários, pode-se concluir pela focalização do Programa, diante da vulnerabilidade social do grupo residente no conjunto. Todos os beneficiários possuem renda igual ou inferior a 3 salários mínimos, enquadrando-se na Faixa 1 do PMCMV. Chama atenção o grande número de famílias que sobrevivem com menos de um salário mínimo $(63,42 \%)$ e que recebem auxilio do governo, especialmente por meio do Programa Bolsa Família (59,35\%).

Há grande ocorrência de chefes de famílias do sexo feminino $(78,86 \%)$ e na faixa etária entre 20 e 45 anos (75,51\%), caracterizando um público jovem e, portanto, em idade produtiva. Mais da metade das famílias (58,26\%) possuem um ou dois filhos, entretanto existem oito famílias com mais de seis filhos, caracterizando um grande adensamento para uma unidade habitacional de apenas dois quartos, o que pode ser interpretado como permanência da inadequação habitacional.

As famílias são provenientes de vários bairros dispersos na malha urbana e, inclusive, da área rural, o que indica que a implantação deste empreendimento gerou um deslocamento rural e intraurbano da população. Parte dos beneficiários $(19,52 \%)$ são famílias que residiam nos "Predinhos dos Araújos", ocupação clandestina situada nas imediações do conjunto (Bairro Santa Clara), cujas condições de moradia eram muito precárias. Mais da metade dos proprietários 


\section{Revista Nacional de}

moravam anteriormente em imóveis alugados (56,1\%), mas há também forte presença de famílias que residiam em imóveis cedidos ou em co-habitação $(37,4 \%)$, ou seja, juntamente com outros membros da família ou na casa de parentes e amigos. É notório ainda o número de famílias (6) que habitavam áreas consideradas de risco.

O índice de desempregados é relativamente baixo (4,92\%), mas há um grande número de empregados em setores de prestação de serviços que exigem baixa qualificação profissional, o que colabora para a permanência da baixa renda da família. Sobressai a forte presença de diaristas, domésticas e trabalhadoras do lar (52,44\%). A baixa escolaridade dos moradores (65,57\% possuem Ensino Fundamental incompleto) é um fator preocupante já que nos dias atuais o nível de escolaridade influencia na conquista de bons empregos e, consequentemente, na possibilidade de ascensão social.

\subsection{Percepção dos moradores quanto à sustentabilidade social do Conjunto Habitacional César Santana Filho}

A sustentabilidade social do Conjunto César Santana Filho foi avaliada a partir da percepção dos residentes, obtida por meio de questionários, com a finalidade de identificar se houve melhoria das condições habitacionais comparativamente às condições existentes nos bairros de origem. Para tanto, foram investigadas três variáveis de sustentabilidade social: interação social, segregação socioespacial e condições de moradia propriamente dita.

\section{a) Interação social}

Segundo os entrevistados, a relação entre vizinhos no conjunto César Santana Filho mostra-se em grande parte satisfatória (50\% - ótimo e $45 \%$ - regular), 


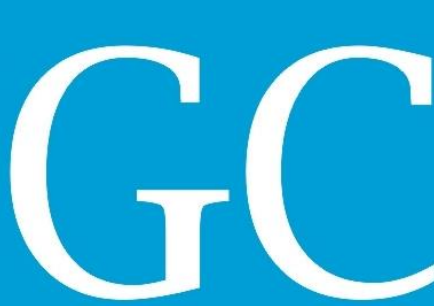

Revista Nacional de

Gerenciamento de Cidades

Tabela 1: Comparação entre as condições de acesso a equipamentos urbanos, ao trabalho e à infraestrutura urbana no Conjunto César Santana e no bairro de origem. Viçosa. 2014.

\begin{tabular}{|c|c|c|}
\hline $\begin{array}{l}\text { PERCEPÇÃO DOS BENEFICÁRIOS QUANTO ÁS } \\
\text { CONDIÇÕES DE ACESSO A EQUIPAMENTOS } \\
\text { URBANOS E AO TRABALHO }\end{array}$ & $\begin{array}{c}\text { CONJUNTO } \\
\text { HABITACIONAL } \\
(\%)\end{array}$ & $\begin{array}{l}\text { BAIRRO DE } \\
\text { ORIGEM } \\
(\%)\end{array}$ \\
\hline Boas condições de acesso ao trabalho: & 38,9 & 94,4 \\
\hline Boas condições de acesso a escolas: & 60,0 & 85,0 \\
\hline Boas condições de acesso a creches: & 39,0 & 68,0 \\
\hline Boas condições de acesso ao Posto de Saúde: & 30,8 & 92,5 \\
\hline Boas condições de acesso aos espaços de lazer: & 37,5 & 97,5 \\
\hline \multicolumn{3}{|l|}{$\begin{array}{l}\text { PERCEPÇĀO DOS BENEFICÁRIOS QUANTO ȦS } \\
\text { CONDIÇÕES DE INFRAESTRUTURA URBANA }\end{array}$} \\
\hline $\begin{array}{l}\text { Boas condições de calçamento das vias no interior do } \\
\text { bairro / conjunto: }\end{array}$ & 75,0 & 90,0 \\
\hline Boas condições de drenagem pluvial: & 49,0 & 87,0 \\
\hline Boas condições de abastecimento de água: & 100,0 & 80,0 \\
\hline Boas condições de esgotamento sanitário: & 80,0 & 77,5 \\
\hline Boas condições de iluminação pública: & 50,0 & 92,0 \\
\hline Boas condições de coleta de lixo: & 64,0 & 97,0 \\
\hline Boas condições do serviço de Correio: & 52,0 & 97,0 \\
\hline Boas condições de telefonia móvel: & 10,0 & 90,0 \\
\hline Boas condições de telefonia fixa: & Não tem & - \\
\hline Boas condições de acesso ao transporte coletivo: & 47,5 & 89,74 \\
\hline
\end{tabular}

Fonte: Resultados da pesquisa.

Como se observa na Tabela 1, as condições de acesso ao trabalho e aos equipamentos urbanos de saúde, educação e lazer são consideradas piores na situação atual de moradia do que nos bairros de origem. Pela falta de uma infraestrutura adequada nos quesitos educacional, de saúde e de lazer, os moradores do Conjunto César Santana Filho ficam muito dependentes dos bairros adjacentes.

No caso do acesso a estabelecimentos comerciais, sobressai a dependência em relação ao Centro da cidade, seja pela variedade dos tipos de comércio, seja por apresentar preços mais baixos comparativamente àqueles praticados nos bairros adjacentes ao conjunto.

As más condições de acesso e de mobilidade urbana contribuem para a segregação social e espacial dos moradores. 


\section{Revista Nacional de}

\section{Condições de moradia}

Mesmo sendo relativamente novas, $82,5 \%$ dos proprietários entrevistados já realizaram alguma reforma nas casas, destacando-se a colocação de piso cerâmico. Também é digno de menção o percentual de moradores que construíram muros, grades ou cercas (20,98\%) e fizeram ampliação na moradia (17,74\%). A necessidade de acréscimo do número de quartos é citado por $35,09 \%$ dos entrevistados e a necessidade de um espaço para refeições (mediante ampliação da cozinha ou construção de copa) é citado por 31,58\%. É perceptível o incômodo dos moradores em relação ao tamanho da cozinha e da área de serviço, que são consideradas "pequenas" para $80 \%$ e $57,9 \%$ dos entrevistados, respectivamente, enquanto na casa anterior elas eram consideradas inadequadas para 37,5\% e $71,42 \%$ dos entrevistados. Mesmo que a construção de novos quartos seja um desejo de muitos moradores, para $77,5 \%$ dos entrevistados o número atual de quartos é considerado adequado, enquanto para $55 \%$ o número de quartos era inadequado na moradia anterior.

Apesar disso, 57,14\% dos entrevistados preferem a moradia atual, o que pode ser interpretado como satisfação em relação ao produto entregue pelo PMCMV, como satisfação com a "casa própria" ou, ainda, pode significar que os beneficiários moravam em condições precárias.

\section{CONCLUSÃo}

Nesse trabalho partiu-se do princípio que a sustentabilidade social de um empreendimento habitacional depende da sua capacidade de promover uma maior integração social e espacial dos seus beneficiários. Nesse sentido, a sustentabilidade social do Conjunto César Santana Filho foi avaliada a partir da percepção dos moradores quanto às condições de moradia e de localização comparadas àquelas que desfrutavam anteriormente à mudança para o conjunto 


\section{Revista Nacional de}

habitacional. Para tanto, foram investigadas três variáveis: interação social, segregação socioespacial e condições de moradia propriamente dita.

Os resultados obtidos indicaram que praticamente todas as condições foram consideradas piores do que aquelas vivenciadas pelos entrevistados nos seus bairros de origem, exceto no caso da unidade habitacional propriamente dita. A situação é mais grave no caso da infraestrutura urbana e das condições de acesso ao próprio empreendimento e aos equipamentos urbanos de saúde, educação (escolas e creches) e lazer. Os serviços de abastecimento de água e esgotamento sanitário foram os únicos bem avaliados pelos entrevistados.

As más condições dos serviços urbanos no interior do empreendimento (drenagem pluvial, telefonia, calçamento, etc.) indicam que o provimento da habitação de interesse social pelo poder público limitou-se à provisão da unidade habitacional, desvinculada de uma política urbana que vise à localização adequada das moradias destinadas à população de baixa renda. Além disso, a falta de espaços de convívio não contribui para a constituição de relações sociais entre os moradores, prejudicando sua integração social.

Enfim, a precariedade das condições de acesso e, portanto, de mobilidade urbana, bem como da infraestrutura urbana e de acesso aos equipamentos de educação, saúde, comércio e lazer isolam os moradores do restante da cidade e reforçam a segregação social e espacial, constituindo-se como fatores que comprometem a sustentabilidade social do empreendimento.

\section{AGRADECIMENTOS}

À FAPEMIG, pelo apoio recebido.

\section{REFERÊNCIAS}

HIRATA, F. 'Minha casa, minha vida': política habitacional e de geração de emprego ou aprofundamento da segregação urbana? Revista Aurora [Online], 3, n. 4, 2011. 
